\title{
Using a Multidisciplinary Team-Based Challenge to Promote Brainstorming and Prototyping of Medical Devices
}

\author{
Arushri Swarup ${ }^{1,2}$, Vicki Komisar ${ }^{1,3}$, J. Christopher Bouwmeester ${ }^{l}$ \\ ${ }^{1}$ Institute of Biomaterials and Biomedical Engineering, University of Toronto; ${ }^{2}$ The Hospital for Sick Children, \\ Toronto; ${ }^{3}$ Toronto Rehabilitation Institute - University Health Network \\ arushri.swarup@mail.utoronto.ca,v.komisar@utoronto.ca,chris.bouwmeester@utoronto.ca
}

\begin{abstract}
Multidisciplinary teams of engineering and life science students are challenged to remove a foreign object from a child's ear canal. Each group is provided with a model ear canal and asked to remove objects of different shapes and materials. The experience of iterative problem solving serves to encourage brainstorming and practice the prototyping process, which each team should complete in their over-arching design projects to be successful. Surveys taken from the students before and after the prototype challenge showed they learned more about the brainstorming method they used, but also learned what worked well for other groups. Student feedback indicates that this activity prepared them to be creative and tackle the larger challenge of developing a solution to their own design project as part of the Biomedical Engineering Capstone Design course.
\end{abstract}

Keywords: Prototypes, Medical Device, Brainstorming, Ear Canal, Cooperative Learning

\section{INTRODUCTION}

The ability to conceptualize, prototype and evaluate solutions is fundamental to undertaking credible engineering design, including the design of medical devices. Within a capstone design course, we emphasized development and testing of prototypes for problem-solving by developing an activity based on removing a foreign object from a child's ear canal. While this challenge was not directly related to any given team's specific design projects, it incorporated the theme of biomedical engineering and medical device design into a miniature challenge that could be tackled during a 3-hour period.

The Biomedical Engineering Minor Capstone Design course offered at the University of Toronto is unique because engineering and non-engineering students collaborate over two semesters on a design project. These multidisciplinary teams have a great advantage because students in Life Science programs (e.g., molecular genetics or neuroscience) bring substantial knowledge of human health to their teams, while the engineering students generally bring more experience with engineering fundamentals and design, including idea generation and prototype development. We therefore created an activity to provide a common foundation for all students that encouraged brainstorming and prototyping during the build phase of the capstone design course

The purpose of this activity was to introduce a diverse class of students to brainstorming and prototyping in a fun and engaging way. The intended outcomes were to: 1) apply brainstorming techniques, 2) recognize important steps in medical device design processes, 3) produce a working prototype, 4) evaluate alternative designs, and 5) verify a preferred solution. Students were instructed to identify key requirements (i.e., do not puncture the ear drum) before using different brainstorming techniques to develop concepts and build prototypes. In order to develop and test the prototypes, model ear canals were provided to give realistic physical constraints to the problem. Each team progressed from a larger, low-fidelity, mock canal to a smaller, high-fidelity, 3D-printed ear canal. The level of difficulty in removing objects was adjusted by placing different shapes and materials in the ear canal models to test the extent to which prototypes met the requirements identified by each team.

This paper describes the core lectures and studio elements involved with our brainstorming and prototyping challenge, as well as how student perceptions of their understanding of brainstorming, prototyping and testing evolved throughout this activity.

\section{BACKGROUND}

A major design experience in the final year of undergraduate engineering studies that uses knowledge and skills from earlier course work and incorporates realistic constraints, defines a "capstone" design project course $[1,2]$. In general terms, this type of course should complete the connection of project- or problem-based learning activities [3] from the first year (cornerstone), through other design activities in intermediate years, to final year (capstone) [4]. The intended outcome of this curriculum is that students will be able to identify basic 
needs, analyze open-ended problems, propose solutions to problems, and evaluate their designs based on realistic testing $[5,6]$.

In this course, the design cycle is presented as a straightforward, iterative process composed of: think, build, and test phases [7]. Each of these phases is expanded to highlight a total of six specific actions. The "think" phase is expanded to: 1) defining the problem with research, interviews, and observations and 2) collecting information to synthesize the function, attributes, and requirements/specifications that can be used to assess whether a solution meets a user's needs. The "build" phase is expanded to: 3) imagine what potential solutions could be and then choose the most promising of these solutions to 4) develop into a plan, prototype, or product. The "test" phase is expanded to: 5) measure a response from a proofof-concept, benchtop, animal, human, or other experiment and 6) improve the design as a result of studying the results and implementing changes.

Ideation often starts with inspiration and imagining what kind of form or structure a solution might have. Realizing that a large volume of ideas are necessary to produce a single good idea, brainstorming [8] is a process that helps to spark the development of new ideas and creates innovation by connect existing ideas. While many methods of brainstorming exist, four techniques were emphasized in this team-based challenge. Specifically:

- The 6-3-5 method [9] was modified for a group of four but still involved each student writing down three ideas on a worksheet for five minutes and then passing the worksheet to the next team member so that after 20 minutes there were 48 ideas generated.

- The theme of biological inspiration was used to trigger unstructured brainstorming by using the website www.asknature.org [10], where ideas inspired by nature are linked to engineering designs or principles. An example of biologically-inspired design would be the how timber beetle larvae inspired the chain saw [11].

- Mind mapping [12] was used as a framework to structure brainstorming in different areas and identify unexplored gaps. For example, a mind map could be created based on engineering disciplines and ideas related to mechanical or electrical engineering would be explored and a gap of chemical engineering ideas could be identified.

- Finally, the question "How might we ...?"[13,14] was asked to stimulate brainstorming. This approach emphasizes practical ideas that focused on how a solution would be solved. For example: How might we create suction to remove hard objects from an ear canal?

Throughout the design process, prototypes are useful tools to communicate ideas, test working solutions, and identify opportunities for iteration $[15,16]$. To encourage active learning, some engineering design courses embed short-duration design challenges, such as in the form of a bootcamp [17] or an introductory exercise for teambuilding at the graduate-level [18]. A separate first-year engineering design course introduces students to prototyping and testing through a tutorial where they develop interventions to improve the handwriting experience for individuals with arthritis, and then evaluate the performance of their interventions with respect to comfort, speed and legibility metrics [19].

\section{METHODS}

The core elements of our approach to teaching brainstorming and prototyping included an introductory lecture on ideation, followed by a 3-hour tutorial in which our prototyping challenge took place. Students were also surveyed before and after the activity to evaluate their perception of their abilities in and the utility of brainstorming and prototyping. The lecture took place in a traditional theater environment, while the prototyping challenge activity used the design studio facilities available to undergraduate students enrolled in the biomedical engineering capstone design course.

\subsection{Core lecture content}

The introductory lecture focused on the actions that each team could use to imagine ideas for solutions to their overall design projects. After a range of brainstorming techniques were presented, students completed an activity in class that focused on practicing one specific technique. The goal of this activity was to incorporate a jigsaw-style [20] cooperative learning activity. The whole class was exposed to four brainstorming techniques:

1) 6-3-5 method [9]

2) biological inspiration [10]

3) mind mapping [12]

4) "How might we ...?" [13,14]

Each technique was assigned to a single team and each team would practice their assigned technique to solve the problem of how to remove a foreign object from an ear canal. This activity was conducted for approximately 20 minutes, followed by a short debrief in which each team discussed their perception of the helpfulness of their assigned brainstorming method for advancing design. An extensive final debrief was also presented at the completion of the prototyping challenge. Therefore, this activity served two purposes: 1) to give students a head start on the brainstorming process before the prototyping challenge occurred in the laboratory period, and 2) to complete the jigsaw activity by sharing with the other teams how well a particular brainstorming method worked in terms of generating good ideas that could be easily prototyped.

After the brainstorming activity was completed in class, each student completed a pre prototyping challenge survey. Students rated their knowledge of each brainstorming 
technique on a scale between unacceptable to excellent (i.e., unacceptable; very poor; poor; satisfactory; good; very good; excellent) and they also ranked, from best to worst, how they felt that each technique would yield results in the (yet to be completed) prototyping challenge. After the prototyping challenge was completed in the design studio, the same survey was given to each student. The only difference was that they now ranked, from best to worst, how they felt that each technique yielded results in the prototyping challenge they just completed. The survey questions are shown in Appendix A.

\subsection{Design of prototype challenge}

At the beginning of the prototyping challenge, a brief overview of the challenge was presented and each team was reminded of which brainstorming technique they were to use during the first 30 minutes of the studio session. Each team was first presented with a low fidelity ear canal model based on an instruction set found on the teachengineering.org website [21]. The model had 1-inch long, 1/2-inch diameter PVC tubing to mimic the ear canal and a membrane on the distal end to represent the ear drum (see Fig. 1). The challenge for each team was to remove objects of various sizes (e.g., gel beads, silicone putty ear plugs, miniature shells, fuzzy pompoms, etc.) without puncturing the ear drum. Each team was given access to a selection of hand tools (e.g., Dremel® tools, wire cutters, scissors, glue guns, tape, etc.) and an assortment of easyto-use construction materials (e.g., wire, springs, balsa wood, wood craft sticks, floral foam, straws, etc.) to create prototypes that could remove the objects used as mockforeign object.

Once students found a way to remove the foreign objects on the low fidelity scale, they had to move to the smaller scale, 3D printed model, which constrained the size of the ear canal to $\sim 5 \mathrm{~mm}$ in diameter (see Fig. 1). After approximately two hours each team had moved from brainstorming to realizing their ideas with quick, easy-toconstruct prototypes. A final showcase of the prototypes created by each team was linked to a class-wide debrief of how the brainstorming technique influence the devices they created. The goal was to complete the jigsaw cooperative learning exercise by sharing the knowledge gained by each team about a specific brainstorming technique they put into practice.

\section{RESULTS AND DISCUSSION}

Descriptive statistics of student perceptions of their understanding of each brainstorming technique before and after the activity are presented in Fig. 2. Only 16 students were enrolled in this course and only 12 participated in both the pre- and post- challenge survey. Given the small sample size of participating students, statistical analyses were not attempted at this preliminary stage.
A
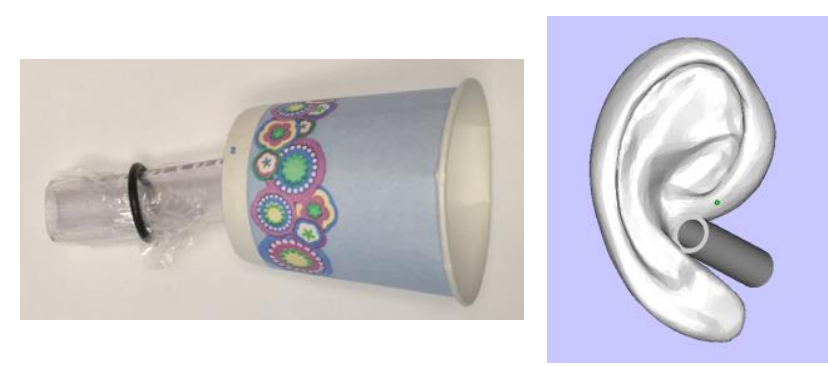

Fig. 1. Ear Models. The low fidelity ear model is shown in Panel A. It is constructed of a Dixie ${ }^{\circledR} 30 z$ bath cup attached to a length of $1 / 2$ inch diameter clear vinyl tubing. An o-ring is used to hold clear plastic wrap on the end to represent the ear drum.

The high fidelity 3D printed model is shown in Panel $\mathrm{B}$. It is made of ABS model material using the uPrint SE Plus 3D printer.

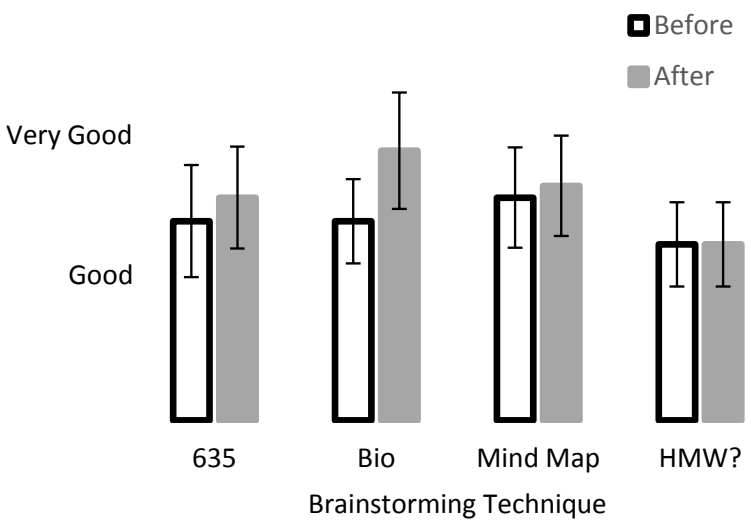

Fig. 2. Student self-evaluation of brainstorming technique knowledge. Bar graphs representing the student's perceived knowledge of each brainstorming technique (modified 6-3-5, biological inspiration, mind mapping, and "How might we ...?") before and after the prototyping challenge. Error bars represent standard error of the mean.

Student perceptions of their knowledge of each brainstorming technique (i.e., modified 6-3-5, mind mapping, "How might we ...?", and biological inspiration) after lecture but before the prototyping activity were consistently between the good and very good levels. After completing the prototyping challenge, the biological inspiration technique received the greatest subjective increase in perceived knowledge (approaching the level of very good). In this case 5 students rated that their knowledge increased and only one student rated a decrease. On the other end of the spectrum, the "How might we ...?" technique had no change in knowledge after the prototyping challenge, as only one student rated an increase but three rated a decrease in knowledge. The other techniques received negligible increases, with a few 
students feeling that their knowledge increased regarding the modified 6-3-5 and mind map techniques.

Given that students only engaged in one brainstorming method during the prototype challenge, their increased perception of knowledge of other methods after the challenge suggests that having each team share their results after the prototype challenge may have contributed to increasing the knowledge of others. These relatively minor increases may stem from the passive sharing of knowledge after the completion of the prototyping challenge. While this overarching activity promoted interaction within and between teams, it would be expected that modifications to the challenge, that incorporated positive interdependence and individual accountability, would further increase the knowledge of students regarding each brainstorming technique after the completion of the prototyping challenge.

Table 1. Ranking of methods that each student felt would yield (before) and did yield (after) the prototyping activity.

Brainstorming techniques ranked best are listed on the top and worst are listed on the bottom.

\begin{tabular}{|c|c|}
\hline Before & After \\
\hline Mind map & Modified 6-3-5 \\
\hline Modified 6-3-5 & Mind map \\
\hline "How might we ...?" & Biological inspiration \\
\hline Biological inspiration & "How might we ...?" \\
\hline
\end{tabular}

The collected results of asking students to rank the brainstorming methods they felt would yield the best results, before participating in the prototyping exercise and the rank they felt yielded the best results, after participating in the prototyping exercise are shown in Table 1.

The questionnaire given to students after completion of the prototyping challenge asked students if they thought that the activity was more effective at delivering information compared to a normal lecture format. Out of 11 responses: 3 strongly agreed, 5 agreed, 2 were neutral, and 1 disagreed. A representative comment from a student who strongly agreed and was:

"It was a really applied way of learning ... and it gives us an idea of the prototyping process before we actually start."

A representative comment from a student who agreed was:

"The diversity of brainstorming techniques was very informative."

\subsection{Limitations}

Some students felt that the challenge did not relate to their individual projects, which was reflected in the following comment:

"It would be more helpful if the topic was geared to our own project rather than the ear canal problem."

CEEA17; Paper 063

University of Toronto; June 4-7, $2017 \quad-4$ of $6-$
Other students, who disagreed or who were neutral on whether the activity was better than a normal lecture format, did not make the connection between this activity and the broader use of prototyping in the ideation process. For example:

"[I] did not understand the different types of prototyping methods. [This activity] was not helpful in understanding of how to prototype real world concepts."

"It would have been much better if we can do things more related to our own project as the prototyping we make during [the] lab might not be useful for us to deliver our final project."

\section{CONCLUSIONS AND FUTURE WORK}

Idea generation and prototype development are critical elements of engineering design processes - generally, and specific to the context of medical device design. We developed and led an activity that aimed to teach both skills in a fun and engaging way. Survey data indicate that this activity made students more comfortable in the brainstorming technique they used and learned from the experiences of other teams. Both the data and results of student feedback suggest that the sharing of knowledge between teams increased individual knowledge and the majority of students prefer the experiential activity to a normal lecture format. Students also indicated that they liked the teamwork and "hands on" aspects of the activity and felt that practicing the creation of low-fidelity prototypes in the beginning of the ideation process was beneficial.

\subsection{Future work}

Keeping with the theme of biomedical devices, the main task of removing a foreign object from an ear canal will continue to be used in the capstone design course and improved by offering more prototyping materials and realistic ear canal analogues. One way to increase the realism of the ear canal would be to use a realistic training simulator for otoscopy; for example, the OtoSim ${ }^{\mathrm{TM}}$ system [22]. The possibility of extending the prototype challenge over multiple lectures to allow for 3D printed designs to be created and tested will also be considered for future challenges.

We will further aim to help students to understand the relationship between the brainstorming techniques discussed in the introductory lecture, the prototyping activity, and the relevance of these activities to the larger picture of engineering design in a medical device context. Key themes that will be communicated include discussing iteration as central to credible engineering design, and reinforcing that early-stage prototyping and testing is central to this iterative process.

Finally, the next iteration of this prototyping challenge will assign each member of the capstone design project 
team to a separate brainstorming group. This would allow each design team to have exposure to all the brainstorming techniques and hopefully improve their design team concept generation.

\section{APPENDIX A: PROTOTYPING CHALLENGE SURVEY}

\section{A.1 Pre Prototyping Challenge Survey}

1) After the in-class brainstorming activity, how would you rate your knowledge of each of the following techniques?

Modified 6-3-5

Mind Map

How might we ...?

Biological inspiration

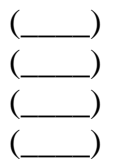

Where: $1=$ unacceptable, $2=$ very poor, $3=$ poor, $4=$ satisfactory, $5=$ good, $6=$ very good, $7=$ excellent

2) Rank the brainstorming techniques in the order you feel will yield the best to worst results

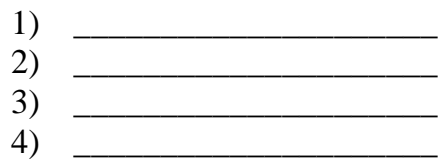

\section{A.2 Post Prototyping Challenge Survey}

1) After completing the prototyping challenge and observing how other groups used their brainstorming techniques, how would you rate your knowledge of each of the following techniques?

Modified 6-3-5
Mind Map
How might we ...?
Biological inspiration

Where: $1=$ unacceptable, $2=$ very poor, $3=$ poor, $4=$ satisfactory, $5=$ good, $6=$ very good, $7=$ excellent

2) Rank the brainstorming techniques in the order you feel yielded the best to worst results

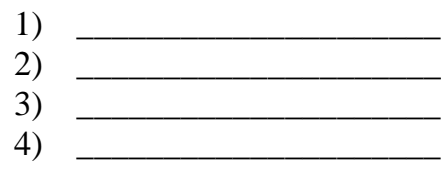

\section{A.3 Feedback Questionnaire}

1) For the prototyping challenge activity, do you think it is a more effective way to deliver the information than a normal lecture format? (circle on of the following)

\author{
Strongly disagree \\ Disagree \\ Neutral \\ Agree
}

Strongly agree

2) In regards to the prototyping challenge activity, can you list at least 2 things that you like and 2 things you didn't like? In which way do you think the activity could be improved?

3) Do you have any other comments?

\section{Acknowledgements}

The authors gratefully acknowledge financial support from the Canadian Institutes of Health Research Operating Grants (CIHR MOP 142178) (VK), the AGE-WELL Network of Centres of Excellence in Technology and Aging Graduate Student Scholarships (VK), and Toronto Rehabilitation Institute Graduate Student Scholarships (VK). VK also gratefullyf acknowledges funding from the University of Toronto's Institute of Biomaterials and Biomedical Engineering to present at CEEA 2017.

\section{References}

[1] Hyman BI. "From Capstone to Cornerstone: A New Paradigm for Design Education". Int J Eng Educ 2001;17:416-20.

[2] Froyd JE, Wankat PC, Smith KA. "Five Major Shifts in 100 Years of Engineering Education". Proc IEEE 2012;100:1344-60.

[3] Dym C, Agogino A, Eris O, Frey D, Leifer L. "Engineering Design Thinking, Teaching, and Learning.". J Eng Educ 2005;94:103-20.

[4] Sheppard K, Gallois B. "The design spine: Revision of the engineering curriculum to include a design experience each semester". Am Soc Eng Educ Annu Conf Proc 1999.

[5] Crawley EF, Malmqvist J, Östlund S, Brodeur DR, Edström K. Rethinking Engineering Education. Cham: Springer International Publishing; 2014.

[6] Taajamaa V, Eskandari M, Karanian B. "O-CDIO: Emphasizing Design Thinking in CDIO Engineering Cycle". Int J Eng Educ 2016;3(B):1530-9.

[7] McCahan S, Anderson P, Kortschot M, Weiss PE, Woodhouse KA. Designing engineers : an introductory text. Wiley; 2015.

[8] Osborn AF. Applied imagination principles and procedures of creative thinking. New York: Scribner; 1953. 
Proc. 2017 Canadian Engineering Education Association (CEEA17) Conf.

[9] Rohrbach B. "Kreativ nach Regeln-Methode 635, eine neue Technik zum Lösen von Problemen".

Absatzwirtschaft 1969.

[10] "AskNature - Innovation Inspired by Nature" https://asknature.org/ (accessed April 21, 2017).

[11] Cox JB. Chain Saw. US2622636A, 1946.

[12] Buzan T, Buzan B. The mind map book : unlock your creativity, boost your memory, change your life. Pearson/BBC Active; 2010.

[13] "Generating How Might We (HMW) Questions from Insights - Northwestern University | Coursera" https://www.coursera.org/learn/leadership-designinnovation/lecture/JMRYd/generating-how-might-wehmw-questions-from-insights (accessed April 27, 2017).

[14] "Design Kit" http://www.designkit.org/methods/3 (accessed April 27, 2017).

[15] Berglund A. Two facets of Innovation in Engineering Education: The interplay of Student Learning and Curricula Design. KTH Royal Institute of Technology, 2013.

[16] Berglund A, Leifer L. "For Whom Are We Prototyping? A Review of the Role of Conceptual Prototyping in Engineering Design Creativity". DS 73-2 Proc 2nd Int Conf Des Creat Vol 2 2012:201-10.

[17] Guo X, Taajamaa V, Yang K, Westerlund T. "Capstone Bootcamp Concept Catalyzing Problem-based Learning". 11th Int CDIO 2015.

[18] "Design for Extreme Affordability" http://extreme.stanford.edu/ (accessed April 20, 2017).

[19] Komisar V, Flood A, Walji N, Irish R, Foster J. Teaching credible validation and verification methods to a large, multidisciplinary first-year engineering design class. CEEA Can. Eng. Educ. Conf., Toronto: 2017.

[20] Barkley EF, Cross KP (Kathryn P, Major CH. Collaborative learning techniques : a handbook for college faculty. Jossey-Bass; 2005.

[21] "Designing a Medical Device to Extract Foreign Bodies from the Ear - Activity" https://www.teachengineering.org/activities/view/uva_e ardevice_act (accessed April 21, 2017).

[22] "OTOSIM" http://otosim.com/ (accessed April 21, 2017).

CEEA17; Paper 063

University of Toronto; June 4-7, $2017 \quad-6$ of $6-$ 